University of Nebraska - Lincoln

DigitalCommons@University of Nebraska - Lincoln

Sociology Department, Faculty Publications

Sociology, Department of

$12-2019$

\title{
Doing family: The reproduction of heterosexuality in accounts of parenthood
}

\author{
Emily Kazyak \\ University of Nebraska-Lincoln, ekazyak2@unl.edu \\ Nicholas K. Park \\ Gavilan College, npark@gavilan.edu
}

Follow this and additional works at: https://digitalcommons.unl.edu/sociologyfacpub

Part of the Family, Life Course, and Society Commons, and the Social Psychology and Interaction Commons

Kazyak, Emily and Park, Nicholas K., "Doing family: The reproduction of heterosexuality in accounts of parenthood" (2019). Sociology Department, Faculty Publications. 732.

https://digitalcommons.unl.edu/sociologyfacpub/732

This Article is brought to you for free and open access by the Sociology, Department of at DigitalCommons@University of Nebraska - Lincoln. It has been accepted for inclusion in Sociology Department, Faculty Publications by an authorized administrator of DigitalCommons@University of Nebraska - Lincoln. 


\title{
Doing family: The reproduction of heterosexuality in accounts of parenthood
}

\author{
Emily Kazyak \\ University of Nebraska-Lincoln, Lincoln, Nebraska USA \\ Nicholas K. Park \\ Gavilan College, Gilroy, California USA

\begin{abstract}
Corresponding author: Emily Kazyak, PhD, Associate Professor, Department of Sociology and NE 68588, USA. Email: ekazyak2@unl.edu

ORCID iD Emily Kazyak https://orcid.org/oooo-ooo2-3488-5914
\end{abstract} \\ Program in Women's and Gender Studies, University of Nebraska-Lincoln, 725 Oldfather Hall, Lincoln,
}

\begin{abstract}
The cultural and legal landscape in the United States has shifted towards increased recognition of LGBQ-parent families. This shift raises questions about the everyday experiences of LGBQ parents and whether the cultural and legal changes also manifest in diminished experiences of discrimination. Drawing on data from 74 interviews with LGBQ parents, we analyze their accounts of whether they are read as a parent by others in their daily interactions. Our findings reveal the ways in which heterosexuality is a key component of how membership to the category of 'parent' is produced in social interactions. Our findings also illustrate how assumptions about heterosexuality are both racialized and gendered. Our focus on accountability foregrounds power in everyday interactions and provides a lens through which to understand how inequality and disempowerment for LGBQ people can persist in American society despite cultural and legal changes.
\end{abstract}

Keywords family, heteronormativity, intersectionality, LGBTQ, sexuality

Published in Journal of Sociology, Special Issue - Experiences of and responses to disempowerment, violence and injustice within the relational lives of Lesbian, Gay, Bisexual, Transgender, and Queer (LGBTQ) people, 18p. Published December 4, 2019. doi:10.1177/1440783319888288

Copyright (C) 2019 Emily Kazyak and Nicholas K. Park; published by SAGE Publications. Used by permission. 
The cultural and legal landscape in the United States has shifted towards increased recognition of Lesbian, Gay, Bisexual, and Queer $(\mathrm{LGBQ})^{1}$ parent families. Until relatively recently, the legal context constrained the ability for LGBQ people to become parents or to be recognized as a legal parent (Kazyak et al., 2018; Shapiro, 2013). As the overall legal landscape has moved from being largely restrictive to granting rights, so too has public opinion about LGBQ parents shifted. Survey research indicates increasing cultural acceptance of LGBQ-parent families and support for LGBQ rights (Fetner, 2016; Powell et al., 2010). How might the changes in social attitudes and laws regarding LGBQ-parent families matter for the everyday experiences of LGBQ parents in the United States? In this article, we draw on data from 74 interviews with LGB parents and analyze their accounts of whether they are read as a parent by others in their daily interactions. We focus on the assessment of parenthood as a lens into understanding the disempowerment and injustice that LGBQ people experience in everyday life. Culturally, LGBQ people have historically not aligned with expectations about the ideal parent in the United States (Smith, 1993). Legally, LGBQ people have also been denied recognition of parenthood (Shapiro, 2013). Thus, the question of being recognized as a parent, whether legally, culturally, or in interactions, is an important one to address to understand the inequalities faced by LGBQ people.

In our analysis, we utilize the theoretical framework that asserts that everyday interactions are crucial to reproducing (or disrupting) social structure (Berger and Luckmann, 1966; Fenstermaker and West, 2002; West and Fenstermaker, 1995; West and Zimmerman, 1987). We are particularly interested in the concept of 'accountability', which, scholars argue, is a key but understudied aspect of both how membership to a social category is produced and how inequalities are reproduced in social interactions (Hollander, 2013). Our findings underscore how heterosexuality is a key component of the ways in which membership in the social category 'parent' is produced in social interactions. We also illustrate how the accomplishment of heterosexuality (and by extension parenthood) is racialized and gendered. We argue that our analysis highlights how inequality can be reproduced at the interactional level, despite changes in the law and cultural attitudes. 


\section{Structures, interactions, and accountability}

Key to sociological thought is an emphasis on 'structures'. Sociologists use the term 'structure' to refer to the 'tendency for patterns of relations to be reproduced' (Sewell, 1992: 3) or the 'patterns of social life that are not reducible to individuals and are durable enough to withstand the whims of individuals who would change them' (Hays, 1994: 6o-1). Scholars refer to both material and non-material aspects of structure, pointing to access to resources as well as cultural meanings in shaping how social life is experienced (Hays, 1994; Sewell, 1992). Additionally, structure works on the individual, interactional and macro level in shaping the social world (Risman, 2004).

For sexuality to be a social structure, as we argue in this article, we would thus expect that there are patterns of social life that are connected to sexuality; specifically, given the historical and societal context of the United States, we should see evidence that the heterosexuality/ homosexuality binary organizes the social world (Canaday, 2009; Ingraham, 1999; Seidman, 2002). We would expect sexuality to shape individual processes (e.g. people construct sexual identities), interactional processes (e.g. accomplishment of sexual identities), and macro-level processes (e.g. access to legal rights varying by sexuality or varying cultural meanings being ascribed to different types of sexualities). For instance, because of the binary, some sexual identities are invisible or perceived as less valid, including bisexuality (Ochs and Rowley, 2009; Scherrer et al., 2015).

In our analysis, we focus on the interactional level and its role in reproducing social structure (Berger and Luckmann, 1966). We are especially interested in the concept of 'accountability', which, scholars argue, is a key but understudied aspect of both how membership in a social category is produced in social interactions and how inequalities are reproduced in social interactions (Fenstermaker and West, 2002; Hollander, 2013; West and Fenstermaker, 1995; West and Zimmerman, 1987). We build on Hollander's (2013) theorization of accountability that entails three processes: orientation, assessment, and enforcement. Her work underscores: that individuals are aware of societal expectations relating to any given category (orientation); that individuals in interactions continually judge themselves and others on whether they meet the expectations of that category (assessment); 
and that individuals then respond according to that judgment (enforcement). We utilize Hollander's framework and focus on the second process entailed in accountability: how others assess LGBQ parents in everyday interactions. Specifically, we ask: when and why do others assess LGBQ parents as being a parent? A focus on this interactional process highlights how the account of parenthood rests on the expectation of heterosexuality.

Importantly, the focus on accountability foregrounds power in interactions and provides a lens through which to understand how inequality is reproduced in interactions. As Hollander (2013: 24) writes: 'Accountability tethers interaction to social structure through the normative expectations for behavior that are linked to social groups.' The normative expectations are based on societal not individual understandings. Thus, the expectations that people hold for others in interactions reflect societal understandings that encompass normative cultural ideals as well as material and institutional codifications of those ideals (Fenstermaker and West, 2002). In this way, our focus on assessments that others make of adults with children to determine whether or not the adults are parents highlights the societal understandings that exist of 'parent' and 'family'.

Our work underscores the interplay between institutional and interactional reproductions of inequality. Despite changes at the institutional level (i.e. LGBQ parents have increased legal recognition of their parenthood), inequalities can persist in the interactional level. Specifically, LGBQ parents are not necessarily always judged as meeting the expectation of what it means to be a 'parent' and thus their families are not always recognized as families in interactions. The degree to which parenthood and heterosexuality remain linked in people's assessments in interactions serves as one example of disempowerment and injustice that LGBQ people experience in their daily lives.

\section{Culture, law, and LGBQ-parent families in the US}

We draw on scholarship that highlights how 'heteronormativity', or the privileging of heterosexuality, operates as an organizing principle of social life (Jackson, 2006; Kitzinger, 2005; Martin and Kazyak, 2009). Sexuality is a social structure given the different cultural 
meanings ascribed to heterosexuality (e.g. normal, natural, the best) and all other forms of sexuality (e.g. abnormal, unnatural, devalued). Moreover, access to material resources, including legal rights and benefits from the state, have historically varied by sexuality, which further illustrates how sexuality is a social structure (Canaday, 2009; Rubin, 1984; Schilt, 2008).

Scholars demonstrate how the normative cultural understanding of 'family' entails a heterosexually married couple raising their biological children - what Smith calls the 'Standard North American Family' (Smith, 1993). The fact that LGBQ identity and parenthood have been understood as incompatible further underscores how the cultural meaning of parent is tied to heterosexuality (Berkowitz and Marsiglio, 2007; Kazyak et al., 2016; Weston, 1991). Research has addressed how LGBQ people negotiate their sexuality and parenthood identities at the individual level (Bergstrom- Lynch, 2015; Lewin, 2009). There is evidence that, increasingly, LGBQ people do not see parenthood as out of reach or incompatible with their sexuality (Patterson and Riskind, 2010). Attitudes of Americans as reported on surveys likewise indicate greater cultural acceptance of LGBQ-parent families (Powell et al., 2010). In addition to focusing on cultural understandings and individual negotiations of identity, scholars have also addressed the legal context in the United States and its impact on LGBQparent families. Until relatively recently, the legal context has restricted or constrained the ability for LGBQ people to become parents or to be recognized as legal parents (Baumle and Compton, 2015; Kazyak and Woodell, 2016; Richman, 2009). Likewise, research has shown how the number and kinds of legal protections for LGBQ-parent families greatly varied across states and resulted in different outcomes for parents depending on their place of residence (Kazyak, 2015; Park et al., 2016; Shapiro et al., 2009). We build on this literature and focus on whether and how inequalities occur at the interactional level.

Our analysis of interactions is informed by the perspective that views families as 'ongoing social accomplishments' (Gubrium and Holstein, 1990). Coupled with our focus on accountability, this perspective draws attention to the fact that individuals make meaning in interactions to assess if someone is a family or a parent. Scholars have focused on the work that LGBQ people have done to make their relationships and families visible (Baker and Elizabeth, 2012; Carroll, 
2018; Oswald, 2002; Pfeffer, 2016). We build on this literature and shift focus to the role that others play in the interactional processes of being held accountable to the social categories of 'parent'. The focus on others and accountability is particularly useful to highlight power and the reproduction of social inequalities. As Gash and Raiskin (2016) argue, the interpretations that other people, particularly institutional gatekeepers like doctors, make about LGBQ-parent families matter a lot for parents to be able to make decisions for their children in these realms. In this way, accountability and the interpretations that happen in interactions can reproduce (or potentially disrupt) inequality (West and Zimmerman, 2009).

We are interested in inequalities related to sexuality and focus on how assumptions about sexuality matter to interactional accounts of parenthood. Yet we argue that gender and race shape the interpretations that others make about sexuality, as our analysis illustrates. Thus our work is also informed by intersectionality scholarship that seeks to understand how systems of oppression and categories of difference are mutually constitutive (Choo and Ferree, 2010; Collins, 2015; McCall, 2005). Our work therefore builds on the call for sexuality scholars to incorporate intersectional inquiries (Moore, 2011). We focus specifically on how accounts of heterosexuality are gendered and racialized in interactions.

\section{Data and methods}

\section{Data collection and analysis}

Our analysis draws on data from 74 in-depth interviews with LGBQ parents. The interview data come from two data sets that each author collected separately for independent studies. The first study (Study 1) consisted of interviews with 55 gay and lesbian parents who are from 32 different families. The second study (Study 2) consisted of 19 interviews with lesbian and bisexual mothers who are from 11 different families. ${ }^{2}$ The parents are diverse in terms of pathways taken to become a parent, geography, class, and race. Additionally, at the time the interviews were conducted, the states in which the participants resided varied in terms of laws and social attitudes. Each study 
had a different focus. Study 1 aimed to understand how state-level legal and social climates influenced decisions about which pathways to take to parenthood. Study 2 aimed to understand how parents make decisions about laws and how parental legal recognition mattered in their everyday lives.

In both studies, participants were recruited through a purposive, convenience sample with several starting points so as not to over-rely on particular social networks (see Table 1 for sample characteristics). Our starting points included national LGBTQ organizations (e.g. Family Equality Council). We also recruited through regional and state LGBTQ organizations (e.g. PFLAG - Parents and Friends of Lesbians and Gays), as well as churches with welcoming LGBTQ-friendly stances. Finally, for both studies, there was a public Facebook page for the study that invited participants and stated that anyone could share. Given the focus of the studies, recruitment was targeted on the following states: California, Nebraska, Missouri, and Iowa. The interviews in Study 1 included questions about which pathway parents took to parenthood and what obstacles they experienced. The interviews in Study 2 included questions about how parents gained information about second-parent adoption laws and whether they perceived that the law mattered in their family's daily interactions. Interviews for Study 1 were conducted in 2011 (3 were conducted in 2008) and the majority of interviews in Study 2 were conducted in 2012 (4 were conducted in 2013). The interviews were audio recorded and transcribed verbatim.

Data analysis was a collaborative, reiterative process that included reading transcripts, coding, and meeting regularly to discuss emerging themes. Although both data sets had been previously analyzed, we discarded all previous codes and began a new analysis of the data with the current focus. We first made sure that there were no people who appeared in both studies (as both researchers recruited in Nebraska). We determined only one couple had participated in both studies and they were treated as one family for this analysis. We then began analysis for the current manuscript by each author reading through transcripts from the other person's study and taking notes on interesting themes that emerged. We developed a list of four broad codes based on these initial readings or what Emerson et al. (1995) refer to as 'open coding'. Through meeting to discuss the themes, we decided to narrow our focus on everyday interactions. We returned to the data and 
Table 1. Sample characteristics.

\begin{tabular}{|c|c|c|c|c|c|c|}
\hline Name & Age & $\begin{array}{c}\text { Race / } \\
\text { ethnicity }\end{array}$ & $\begin{array}{c}\text { Number } \\
\text { of children }\end{array}$ & Method ${ }^{\mathrm{b}}$ & $\begin{array}{l}\text { Household } \\
\text { income }\end{array}$ & State \\
\hline Becky and Susan & $31 / 32$ & $\mathrm{~W} / \mathrm{W}$ & 1 & I & $<\$ 50,000$ & $\mathrm{NE}$ \\
\hline Leslie & 47 / 33 & $\mathrm{~W} / \mathrm{W}$ & 1 & FA & $<\$ 50,000$ & $\mathrm{NE}$ \\
\hline Peter and Dean & 38 / 39 & $\mathrm{~W} / \mathrm{W}$ & 1 & $\mathrm{~S}$ & $>\$ 100,000$ & $\mathrm{NE}$ \\
\hline Allan ${ }^{c}$ & 50 & W & 1 & I & $\$ 50,000-\$ 100,000$ & $\mathrm{NE}$ \\
\hline Linda & 33 & $\mathrm{~W}$ & 1 & I & $<\$ 50,000$ & $\mathrm{NE}$ \\
\hline Karen and Jennifer & 37 / 39 & $\mathrm{~W} / \mathrm{W}$ & 2 & IVF & $>\$ 100,000$ & $\mathrm{NE}$ \\
\hline Ashley $^{\mathrm{d}}$ & 44 & $\mathrm{~W} / \mathrm{W}$ & 1 & I & $\$ 50,000-\$ 100,000$ & $\mathrm{NE}$ \\
\hline Katie & 40 & $\mathrm{~W} / \mathrm{W}$ & 1 & I & $<\$ 50,000$ & $\mathrm{NE}$ \\
\hline Shelly and Natalie & $39 / 38$ & $\mathrm{~W} / \mathrm{W}$ & 1 & I & $\$ 50,000-\$ 100,000$ & $\mathrm{NE}$ \\
\hline Megan and Judye & $36 / 46$ & $\mathrm{~W} / \mathrm{W}$ & 2 & I & $\$ 50,000-\$ 100,000$ & $\mathrm{NE}$ \\
\hline Samantha and Charlotte & $34 / 33$ & $\mathrm{~W} / \mathrm{H}$ & 1 & FA & $\$ 50,000-\$ 100,000$ & $\mathrm{NE}$ \\
\hline Ellen & 41 & W & 2 & I & $>\$ 100,000$ & $\mathrm{CA}$ \\
\hline Andrew and Michael & $46 / 42$ & $\mathrm{~W} / \mathrm{W}$ & 1 & FA & $\$ 50,000-\$ 100,000$ & $\mathrm{CA}$ \\
\hline Bruce & 35 & $\mathrm{~W}$ & 1 & A & $>\$ 100,000$ & $\mathrm{CA}$ \\
\hline Mark and Carl & 37 / 36 & $\mathrm{~J} / \mathrm{W}$ & 1 & S & $>\$ 100,000$ & $\mathrm{CA}$ \\
\hline Jason and Malcolm & 45 / 51 & $\mathrm{~W} / \mathrm{W}$ & 1 & S & $>\$ 100,000$ & $\mathrm{CA}$ \\
\hline Amber and Miranda & $43 / 46$ & $\mathrm{~W} / \mathrm{W}$ & 2 & FA & $>\$ 100,000$ & $\mathrm{CA}$ \\
\hline Luke & 45 & W & 1 & A & $>\$ 100,000$ & $\mathrm{CA}$ \\
\hline Nathan and Richard & $40 / 47$ & $\mathrm{~W} / \mathrm{W}$ & 1 & $\mathrm{~S}$ & $>\$ 100,000$ & $\mathrm{CA}$ \\
\hline Paul & 48 & W & 1 & A & $>\$ 100,000$ & $\mathrm{CA}$ \\
\hline Williame and Keith & $60 / 44$ & $\mathrm{~W} / \mathrm{A}$ & 1 & S & $>\$ 100,000$ & $\mathrm{CA}$ \\
\hline Zach and Jeremy & $32 / 36$ & $\mathrm{~W} / \mathrm{W}$ & 1 & $\mathrm{~A}$ & $>\$ 100,000$ & $\mathrm{CA}$ \\
\hline Kevin and Dylan & $46 / 46$ & $\mathrm{~W} / \mathrm{W}$ & 1 & A & $>\$ 100,000$ & $\mathrm{CA}$ \\
\hline Cheryl & 36 & $\mathrm{H}$ & 2 & FA & $>\$ 100,000$ & $\mathrm{CA}$ \\
\hline Melanie and Nora & $54 / 53$ & $\mathrm{~W} / \mathrm{W}$ & 2 & I & $>\$ 100,000$ & $\mathrm{CA}$ \\
\hline Sean and Eric & $46 / 45$ & $\mathrm{~W} / \mathrm{W}$ & 1 & FA & $>\$ 100,000$ & $\mathrm{CA}$ \\
\hline Oliver and Steve & $33 / 34$ & $\mathrm{~W} / \mathrm{W}$ & 1 & A & $>\$ 100,000$ & $\mathrm{CA}$ \\
\hline Kathy & 48 & W & 2 & I & $>\$ 100,000$ & $\mathrm{CA}$ \\
\hline Nicole and Teresa & $53 / 56$ & $\mathrm{~W} / \mathrm{W}$ & 1 & $\mathrm{~A}$ & $>\$ 100,000$ & $\mathrm{CA}$ \\
\hline Jackie and Amy & $31 / 32$ & $\mathrm{~W} / \mathrm{W}$ & 1 & I & $<\$ 50,000$ & $\mathrm{CA}$ \\
\hline Betty and Cassie & $43 / 48$ & $\mathrm{~W} / \mathrm{J}$ & 1 & I & $>\$ 100,000$ & $\mathrm{CA}$ \\
\hline Janet & 48 & $\mathrm{~W}$ & 1 & $\mathrm{~A}$ & $>\$ 100,000$ & $\mathrm{NE}$ \\
\hline Luanne & 44 & $\mathrm{~W}$ & 1 & I & $\$ 50,000-\$ 100,000$ & $\mathrm{NE}$ \\
\hline Angela and Mary & 32 / 32 & $\mathrm{~W} / \mathrm{W}$ & 1 & I & $>\$ 100,000$ & $\mathrm{NE}$ \\
\hline Anne & 47 & W & 1 & I & $<\$ 50,000$ & $\mathrm{NE}$ \\
\hline Victoria and Grace & $38 / 34$ & $\mathrm{~W} / \mathrm{W}$ & 3 & I & $\$ 50,000-\$ 100,000$ & MO \\
\hline Cathy and Harriet & $34 / 34$ & $\mathrm{~W} / \mathrm{W}$ & 1 & I & $\$ 50,000-\$ 100,000$ & MO \\
\hline Darcie and Linda & $38 / 43$ & $\mathrm{~W} / \mathrm{W}$ & 1 & I & $\$ 50,000-\$ 100,000$ & IA \\
\hline Elizabeth & 43 & W & 1 & I & $\$ 50,000-\$ 100,000$ & IA \\
\hline Melanie & 29 & $\mathrm{~W}$ & 1 & I & $\$ 50,000-\$ 100,000$ & MO \\
\hline Jan and Tanya & $43 / 36$ & $\mathrm{~W} / \mathrm{W}$ & 2 & I & $\$ 50,000-\$ 100,000$ & $\mathrm{NE}$ \\
\hline Shawna and Joyce & $33 / 32$ & $\mathrm{~W} / \mathrm{W}$ & 2 & I & $>\$ 100,000$ & MO \\
\hline Pamela and Robyn & $44 / 44$ & $\mathrm{~W} / \mathrm{W}$ & 1 & I & $<\$ 50,000$ & IA \\
\hline Erin $^{f}$ and Phoebe & $-/ 23$ & $\mathrm{~W} / \mathrm{W}$ & 1 & I & $<\$ 50,000$ & $\mathrm{NE}$ \\
\hline Ellen and Nikki & $33 / 36$ & $\mathrm{~W} / \mathrm{BR}$ & 1 & I & $\$ 50,000-\$ 100,000$ & $\mathrm{NE}$ \\
\hline
\end{tabular}

a. $\mathrm{W}=$ White, $\mathrm{J}=$ Jewish, $\mathrm{H}=$ Hispanic, $\mathrm{A}=$ Asian, $\mathrm{BR}=$ Biracial.

b. $\mathrm{A}=$ Adoption, $\mathrm{FA}=$ Foster-adoption, $\mathrm{I}=$ Insemination, $\mathrm{S}=$ Surrogacy.

c. Allan was a donor and co-parent with Shelly and Natalie.

d. Ashley and Katie have separate rows because they were no longer a couple at time of interview.

e. William and Judy had adult children from previous relationships not reported here.

f. Erin declined to provide her age. 
began what Emerson et al. (1995) refer to as 'focused' coding of all transcripts to identify more specific themes within these broad codes that eventually became the findings below.

There are limitations to our approach of combining interview data from two separate studies. Since participants were asked different questions, we are not able to offer analyses that include comparison across all participants for every scenario discussed here or report numeric trends. For instance, many, but not all participants talked about their experiences in health care settings at some point in the interviews. We cannot make claims about how many other participants had similar experiences since we did not ask each participant specifically about their experience with health care professionals. Likewise, one interesting thing that emerged from our analysis is the degree to which some participants noted not being recognized as a parent, even by people they assumed to be LGBQ-friendly. If we had asked all participants to reflect on their experiences with people they know to LGBQ-friendly (versus unknown versus known to be anti-LGBQ), we might have been able to determine patterns. Finally, participants might have shared different stories in the interviews had the interview guides been structured with this particular research question in mind. Despite the different foci and interview guides utilized in each study, in all of the interviews, the participants shared reflections about their experiences with family recognition in everyday interactions. In fact, it is partly because we were struck by the similarities of these reflections (despite the different foci of the studies and de-

spite the fact that participants were living in very different social and legal contexts) that we decided to collaborate on the current analysis.

\section{Profile of participants}

The total sample includes 74 LGBQ parents from 43 different families and includes 24 gay men, 43 lesbian women, and 7 bisexual women. All of the parents had at least one child after coming out or in the context of a same-sex relationship. The routes they took to parenthood were diverse, as our sample consisted of people who became parents via donor insemination ( 24 families), surrogacy ( 5 families), private adoption ( 8 families), and public/foster-adoption ( 6 families). The families lived in four different states in the Midwest and West Coast, with the majority living in either Nebraska (16 families) or California 
(20 families), and 4 and 3 families living in Missouri and Iowa, respectively. These regions reflect quite different legal and social climates regarding LGBTQ parenting. Most of the participants described their place of residence as urban or suburban, but four families were living in small towns or rural areas. Participants ranged from 31 to 60 years old with the average age being 40 years old. Although the participants were predominantly White, two identified as Hispanic, two as Jewish, one as Asian American, and one as Biracial. There was more variation with regard to class: with 9 families reporting annual family income below \$50,000, 11 families reporting between $\$ 50,000$ and $\$ 100,000$, and 23 families reporting earning over $\$ 100,000$. Of the families, two had a family income of less than $\$ 30,000$. The sample was highly educated, with 12 reporting having a high school diploma, 19 having four-year college degree, and 33 having a graduate degree or higher. In terms family composition, 31 of the families in the sample had one child; 8 had two children, and 1 family had three children. The age of children at the time of the interview ranged from 3 months to 19 years old and about half of the children (57\%) were under the age of 5 . With regard to legal parental status, the majority of parents were legally recognized as parents, but seven families had at least one parent with no legal parental rights.

\section{Heterosexuality and the accomplishment of parenthood}

In this section we outline how (hetero)sexuality is a key component to the ways in which membership to the social category parent is produced in social interactions. There are two types of interactions that illustrate this phenomenon. First, in interactions when participants are alone with their child, others read them as a parent and assume that they are heterosexual. Second, in interactions when participants are with their same-gender partner and their child, strangers do not immediately read them both as parents. Instead, one is assumed to be a friend or a family member, such as a sister or brother.

Many participants described interactions when they were alone with their children. They discussed how in these interactions, others often assumed they were heterosexual. For instance, Malcolm recalled eating at a restaurant with his daughter Parker: 'Parker was doing something and the waitress said "If her mom was here, she wouldn't 
be letting her do that."' In this interaction, the waitress makes the assumption that Parker has a mother and thus that Malcolm is heterosexual. Likewise, Nicole asserted that in interactions with strangers: 'if you start a conversation by talking about your kid . . . they're more likely to assume that you are married and that you're heterosexual and that you have a husband'. Nicole gave the example of a recent interaction she had with the person sitting next to her on a plane: 'We started talking about the kid, and then she asked about my husband. I said "Well actually I'm married to a woman and there's two of us, there's two women, you know, parents."' As illustrated in this interaction, the passenger held Nicole accountable to the expectation of heterosexuality upon hearing that she was a parent. Heterosexuality is embedded in the social category 'parent'. Nicole explained that the person was 'mortified', 'embarrassed', and felt she 'should have known better' than to ask about a husband because 'it turns out that she has a gay daughter who has a kid'. Thus, Nicole's story also illustrates how these accounts that link parenthood and heterosexuality can be reproduced in social interactions despite an individual's intentions.

Even when same-sex couples are both present with their children, it is difficult for them to both be read as parents, which further underscores how the accomplishment of 'parent' rests on heterosexuality. In these interactions, one of the parents is often either read as a family member (e.g. sister, brother, cousin, grandparent) or as a friend. For instance, Jackie explained that she and her spouse 'get mistaken for sisters' when in public with their child. Erin and Phoebe also discussed being asked by strangers: 'Who is mom?' in interactions when they are both together with their son. Couples with an age gap between spouses reported that the older parent is assumed to be a grandparent. Linda (whose spouse is 14 years older than her) remarked that she felt her family is 'a little bit invisible' in interactions and that 'a lot of people assumed that [my spouse] was [my daughter's] grandma'. Whereas partners of the same age were read as siblings or friends, those who had a larger age gap were read as a parent and grandparent. These examples demonstrate that when two parents of the same gender are with their child in public, only one of them is read as a parent.

Additionally, the experiences that our participants shared with regard to how others referred to their child's egg donor or sperm donor further illustrate how the account of heterosexuality exists even 
when two parents of the same gender are together. For instance, Peter talked about one of his neighbors who 'insists on referring to [my son's] egg donor as his mom'. He reflected: 'When you say he doesn't have a mom, that's more like he is missing something and I think that's the way the world perceives it. [That] he is missing a mother.' Lesbian participants who had children via donor insemination likewise said others would often refer to the sperm donor as dad. These narratives illustrate the degree to which heterosexuality serves as a structuring principle in social life insofar as the account of family as heterosexual is difficult to change. It is so salient to an account that even when it is disrupted (i.e. even when there are two dads), the account of having a mom (i.e. calling the egg donor the child's mother or saying that the child does have a mom but that she is missing) still exists.

Finally, consider the following stories that all center on interactions when flying, when determining who is and is not a family has consequences in terms of security and boarding procedures. Amy and Jackie recalled having trouble at the airport during family boarding because the gate agent 'was grilling us about whether we were actually eligible for family boarding' and asked 'Who's the mother?' When they replied that 'We both are', the agent said they couldn't both be the mother and again asked 'Who is the mother?' Similarly, Dylan and Kevin described an interaction with a ticket agent who was initially reluctant to provide them a family pass through security because it was only 'for families'. Additionally, Malcolm says: 'Going through customs as a family, people are always like "Why are two guys with kids standing there ... why are you here?"' The response of "why are you here?' indicates the degree to which two people of the same gender with a child are not both read as parents.

Indeed, Keith and William explained that when flying internationally and going through customs, they strategically have one of them take the child and, as Keith put it, 'have the other parent go through separate' (rather than attempting to all go through together). Keith explained that this strategy has meant that they have not 'run into issues' and have been able to 'avoid hassles'. He refers to 'issues' and 'hassles' that other same-gender couples with children whom he knows have experienced, including one where a lesbian couple: 'was given a lot of grief from the U.S. Customs ... [the custom agent] kept asking where the dad is. [The custom agent] made a big deal about that and really hassled them.' We argue that these narratives underscore how 
heterosexuality is a key part of the account of parenthood. In each of these interactions, a stranger understood only one person as a parent (e.g. 'Who's the mom?') and assumed the existence of a different-gender parent who was absent (e.g. 'Where [is] the dad?'). These stories underscore how accounts of parenthood rest on heterosexuality insofar as two people of the same gender with a child have difficulty achieving the accomplishment of parents. Rather, as Allan put it: 'It's like . . . people write their own scenarios for our relationships.' Importantly, those scenarios or accounts are deeply imbedded with heterosexuality.

\section{Heterosexuality: racialized and gendered}

In this section we show how the accomplishment of parenthood and heterosexuality is racialized and gendered. To begin, we address how race plays a role in accounts of parenthood. In interactions when participants are alone with their child, those participants who are perceived to be the same race as their child are seen as a parent; in contrast, those who are perceived to be of a different race than their child are not always seen as a parent. Charlotte and Samantha, an interracial couple raising a White child whom they adopted from the foster care system, illustrate this well. Charlotte, who identified as Hispanic, and Samantha, who identified as White, recounted how strangers often assume that their daughter is biologically connected to Samantha because they both appear White. Samantha explained: 'When people look at us, people tend to think that [our daughter] comes from me.' Charlotte agreed, noting: 'Yeah, [my daughter] and I don't look very much alike.' Samantha responded: 'No. She does not share your ethnic background.' As their exchange illustrates, people assume that their daughter 'comes from' Samantha (i.e. that Samantha is her biological mother); they do not assume the same about Charlotte because she and her daughter do not share the same ethnic background. Their exchange thus underscores how race matters for the accomplishment of parenthood. Samantha, but not Charlotte, is assumed to be the mother because she and her child are perceived to be of the same race. Importantly, this account of parenthood also rests on the assumption of heterosexuality in that their shared racial background is assumed to be the result of a biological connection between mother and child. 
Likewise, Amber's experience demonstrates how parenthood, heterosexuality, and race are intertwined in people's assessments. Amber and her adopted son are both White. She discussed that when she is alone with her child, others assume that she is a parent and heterosexual insofar as they assume that she is biologically related to her child. She told the following story about an interaction she had with a doctor who 'did not know that [my son] was adopted': '[The doctor] is talking about how [my son] was exposed to nine different drugs in utero ... and he doesn't flinch and he doesn't say anything ... and then he goes, "Did you breastfeed?"' Amber said that she responded by saying: 'I don't know, [my son] was adopted.' The doctor responded with: 'Oh, no wonder you're here. I couldn't figure out why somebody who did that many drugs still would be sitting here in front of me.' This interaction highlights how the doctor assumed that Amber had a biological connection to her child given that she and her child are both White. If her child was of a different race, the assumption of a biological tie would be less likely to have been made.

Consider the experiences of Nikki, who identified as multiracial, and her discussions of parenting her multiracial son. Nikki's spouse Ellen, who is White, gave birth to their son and they used a donor who racially matched Nikki. Nikki commented that their friends often remark about her son: 'He looks just like you' despite her not being biologically connected to him. She further explained that perceived similarity is 'nice' in part because 'if we're out in public . . people won't think he's kidnapped'. She contrasts these interactions to her experiences growing up and commented: 'People didn't know that I belonged to my mom because I don't look anything like her because my mom is White and I'm not.' Nikki's story further illustrates how race matters in the assumptions that people make about parenthood in interactions. These stories highlight the cultural assumption of biological ties between parent and child. As our data show, whether people perceived that a biological tie existed depended on race.

The accounts of parenthood that rest on heterosexuality are not only racialized, but are also gendered. We highlight two interactional processes that highlight the gendered accounts of heterosexual parenthood. First, in interactions when alone with their children, gay men (but not lesbian women) are assumed to be a less important or a nonprimary parent. The gay men in our sample discussed interactions in 
which they encountered assumptions not only that they had a wife, but that, as fathers, their parenting role was less central or important. As Peter notes: 'Everything in our society is: moms are parents and dads are glorified babysitters.' Zach agreed saying: 'There are abysmally low concepts for what a father should do.' He gave an example of when someone said, in response to seeing him pushing his child in a stroller: 'You must be a really good Dad, that's really nice of you.' Zach commented: 'If this is what your opinion is of a great dad, this is a pretty sad state of affairs for fathers.'

Similarly, Dylan, a stay-at-home-dad, recounted his experiences taking his daughter to the park during the day: 'I can't tell you how many times some of the [other dads] are, "Oh, you pulled the short straw, too." Like it's this temporary thing that I have to be at the park with my daughter during the workday. And I'm like, "Nom this is what I do." Dylan is both read as a heterosexual father and a secondary caretaker who 'pulled the short straw too' and thus he, rather than the assumed mother, has to be at the park with his daughter. The account in this interaction works to make his queerness invisible insofar as he is assumed to be a father who is parenting with a woman. The account also reinforces a gendered assumption that women are the primary caretakers of children and simultaneously devalues that role. Other fathers discussed strangers making comments about how, as Richard said, it was 'mom's day off' in response to seeing them with their children. Again, the account of 'mom's day off' highlights the assumption of heterosexuality and the gendered assumption that the 'mom' is the primary caretaker whose spouse is giving her a 'day off'.

Further, the accomplishment of heterosexuality is also gendered given how participants' perceived gender presentation works to either disrupt or secure accounts of parenthood. For participants who are perceived as having a normative gender presentation, when out alone with their child(ren), people read them as parents and heterosexuality is assumed. Susan, who described herself as 'femme,' noted: 'When I am out at the store with [my son], people think that I am just another straight woman with her child.' The fact that Susan is perceived as feminine and as having a normative gender presentation leads to others also assuming that she is a parent when she is alone with her child; importantly, others assume she is a 'straight' parent. In contrast, Susan's partner, Becky, who described herself as 'pretty 
butch looking', explained: 'I've gotten weird looks before if [my son] calls me momma.' Unlike Susan, Becky is perceived as having a nonnormative gender presentation and as more masculine. As a result, it is more difficult for people to see her as a parent when she is alone with her child, which is why she gets 'weird looks' when her son references her as a parent. In this way, when participants are seen as nonheterosexual based on perceptions of their gender performance, it disrupts assumptions of heterosexuality, which in turn disrupts assumptions of parenthood.

Consider another example that comes from Luke, who is perceived as having a more feminine gender presentation. Luke described being out at a Castro Street Fair with his child who 'was starting to cry about something and having a little temper tantrum'. Luke described how 'a lesbian woman came over and asked, "Oh, is he lost?"' As Luke explained: 'She wasn't being mean... . . It [just] never dawned on her that I might actually be the father.' We argue that in this interaction, the woman assumed that Luke was a gay man because he was in the Castro (a gay neighborhood in San Francisco) and had a more feminine gender performance. Since he was perceived as gay, he was thus not assumed to be a parent. These stories underscore how being read as a parent in interactions is tied to an assumption of heterosexuality, which in turn is either bolstered or disrupted by perceptions of gender.

The perception of gender presentation also mattered in interactions when couples were together with their children. Recall Charlotte and Samantha, an interracial couple we introduced above. The fact that only Samantha is read as a mother is not just the result of their perceived race, but also of their perceived gender presentation. They both described themselves as more feminine, 'nonthreatening' (Charlotte) and 'looking like any other straight lady'. In reference to the image of a more masculine lesbian woman, Charlotte said that: 'stereotypically we don't look like we fit'.

In contrast, recall Susan and Becky who described themselves as 'femme' and 'pretty butch', respectively. When they are together with their son, they think others actually do see them as a queer family, or as Becky put it: 'They know [our son] is coming from a different [kind of] family.' Susan agreed, saying: 'Now when we are out as a family, people know.' We argue that the difference between how Susan and Becky (who are seen as a butch-femme couple) are perceived when 
with their son versus how Charlotte and Samantha (who are both seen as feminine) are perceived highlights how gender presentation matters for the accomplishment of family.

Likewise, the discussions from Natalie, Shelly, and Allan, who are co-parenting a son, further corroborate the gendered nature of accounts of heterosexuality and parenthood. Allan is perceived as masculine, Natalie is perceived as feminine, and Shelly is perceived as butch. When Allan and Natalie are together with their son, they are read as heterosexual parents; Allan noted that in these interactions, 'everybody thinks that we are a married couple'. Natalie corroborated Allan's interpretation of how people viewed them as a couple. In contrast, when all three of them are together or when Natalie and Shelly are together with their son, the assumption of heterosexuality is disrupted. Allan attributed this in part to Shelly's gender presentation, saying: 'She is noticeable wherever she goes.' He thinks that when they are all together 'there is no denying what we are'. In this way, the visibility of them as a queer family may have been due to Shelly's butch gender presentation.

\section{Discussion and conclusion}

Our work raises questions about whether people's everyday experiences would change as a result of changes in the larger social structure (i.e. culture and laws). We argue that our analysis points to a messy relationship between law, culture, and daily interactions. The participants in our studies lived in states with different legal and social climates regarding LGBQ families. Yet we were struck by how similar people's experiences in everyday interactions were, regardless of the legal and social context in which they lived. Specifically, in interactions when participants were alone with their children, others read them as a parent only because of the assumption of heterosexuality. This occurred even for participants who were living in favorable social and legal climates. Whenever the assumption of heterosexuality was disrupted (i.e. when couples were together or when an individual appeared to have a non-normative gender presentation), participants expressed that others were less able to immediately read them as parents. We thus argue that heterosexuality is a key component in 
how membership to the social category 'parent' is established in American society. Our work suggests how inequalities based on sexuality can persist despite cultural and legal changes.

In this way, our analysis sheds light on the importance of focusing on the interactional level, and on the process of accountability, to fully understand how power operates, how inequalities are perpetuated, and how LGBQ people experience disempowerment and injustice in their daily lives. Importantly, a focus on interactions and accountability illustrates that experiences of disempowerment and discrimination are not always animated by overt anti-LGBQ hostility (Kitizinger, 2005). Indeed, recall Nicole's experience with a woman sitting next to her on the plane who asked about her husband after hearing that Nicole was a parent. That woman herself had a lesbian daughter who was a parent, yet in that interaction, she still reproduced the account that equates parent with heterosexual. Likewise, Luke's experience with his child at the Castro Street Fair, when a lesbian woman approached his child who was crying to ask if the child was lost, further illustrates how it is not always anti-LGBQ hostility that animates the interactionally produced account that parents are heterosexual. That this account can be produced by a lesbian woman and by a heterosexual woman with a lesbian daughter who is a parent indicates how pervasive the link between heterosexuality and parenthood is, despite larger cultural and legal changes that have delinked those categories. The narratives from our respondents indicate that not just overt hostility negatively impacts their daily lives, as even those with positive views of LGBQ-parent families contribute to the invisibility of LGBQ parents in unintended ways. The meanings produced in interactions about parenthood, sexuality, gender, and race make it difficult for LGBQ-parent families to navigate everyday life and be perceived as legitimate parents.

Our analysis opens up questions that can be explored in future research about how accounts might ultimately shift. Some scholars argue that the increasing visibility of same-sex couples who are parents may work to build more inclusive and less heteronormative understandings of family (Bernstein, 2015; Carroll, 2018). Carroll's (2018) research, for instance, focuses on how gay men who are parents do a lot of work to create more visibility for their families. Future work can explore whether and how changes in self-accounts (i.e. LGBQ people see themselves as a parent and their family as a family) translate 
to changes in how others hold LGBQ people accountable in everyday interactions. Moreover, future work should address the fact that, despite increasing legal and social acceptance for LGBTQ people in the United States and globally, a backlash against such progress has occurred and can continue to do so as well (Jones, 2017a).

Our analysis extends discussions of heteronormativity insofar as it illustrates how accounts of heterosexuality are racialized and gendered. As we showed, in interactions when participants are alone with their child, those participants who are perceived to be the same race as their child are seen as a parent; in contrast, those who are perceived to be of a different race than their child are not always seen as a parent. Our work indicates that the accomplishment of heterosexuality is achieved partly through racialization and, when dyads are perceived as being of the same race, the heterosexuality of the parent is bolstered. Further, our findings illustrate the gendered accounts of heterosexual parenthood insofar as gay men were assumed to be a less important or primary parent (compared to an assumed mother), a finding which corroborates Carroll's (2018) research. The perceived gender performance of participants also mattered. When participants are seen as non-heterosexual based on perceptions of their non-normative gender performance, it disrupts assumptions of heterosexuality, which in turn disrupts assumptions of parenthood. Our work addresses the racialized and gendered nature of heterosexuality and thus builds on the increased attention to intersectionality in studies of sexuality (Moore, 2011).

Some of our findings may also relate to stigma and devaluing of adoptive families. Past research has argued that adoption is culturally perceived as second best (Fisher, 2003) and the ideal family remains both heteronormative and biocentric (Suter et al., 2011). Due to these cultural notions about adoption, members of adoptive families continue to experience micro-aggressions (Baden, 2016) and many potential parents decide against adoption as a pathway to parenthood (Slauson-Blevins and Park, 2016). Furthermore, adoptive parents have been found to feel stigmatized for not having a biological connection to their children; these perceptions and how they are internalized differ by gender and sexual orientation (Goldberg et al., 2011). Future research should continue to examine the role that adoption stigma plays in the accomplishment of parenthood as it relates to gender, race, and sexuality. 
Finally, our research builds on family scholarship that analyzes families as 'ongoing social accomplishments' (Gubrium and Holstein, 1990; Pfeffer, 2016). Being read as a parent is an interactional process. Those parents and families who are understood as outside of the 'Standard North American Family' that Dorothy Smith identified (1993), including the parents represented in our studies, face marginalization. Our work shows the processes by which this marginalization manifests for LGBQ parents in everyday interactions. Future work could continue to compare across groups of marginalized parents, such as immigrant parents or single parents, to better analyze the similarities and differences with regard to both experiences of disempowerment and strategies parents might utilize to combat marginalization (e.g. Al-deen and Windle, 2017; Nelson, 2006). Further, future work can continue to explore how others (i.e. non-marginalized people) respond in interactions. Future scholarship can also continue to address and document the consequences of whether or not LGBQ parents are seen as parents in interactions to bolster the importance of focusing on the interactional level to understand the perpetuation of inequality.

Funding The authors received no financial support for the research, authorship, or publication of this article.

\section{Notes}

1. We use the term 'LGBQ' when discussing the legal and cultural landscape in the United States as it relates to regulating sexuality and parenting. We use this term because the landscape impacts a range of non-heterosexual individuals who may self-identify their sexual orientation as lesbian, gay, bisexual, or queer. When we are referring to our sample specifically, we use the term 'LGB' to reflect how participants in our research studies self-identified their sexual orientation. For work focused on intersex individuals, see Jones (2017b). For work focused on transgender individuals, see Pfeffer (2016) Queering Families.

2. For more information about Study 1, see Park et al. (2016). For more information about Study 2, see Kazyak (2015).

\section{References}

Al-deen, T.J. and J. Windle (2017) “I Feel Sometimes I Am a Bad Mother”: The Affective Dimension of Immigrant Mothers' Involvement in their Children's Schooling', Journal of Sociology 53(1): 110-26. 
Baden, A. (2016) 'Do You Know Your Real Parents? Adoption Microaggressions', Adoption Quarterly 19: 1-15.

Baker, M. and V. Elizabeth (2012) 'A "Brave Thing to Do" or a Normative Practice? Marriage after Long-term Cohabitation', Journal of Sociology 50: 393-407.

Baumle, A.K. and D.R. Compton (2015) Legalizing LGBT Families: How the Law Shapes Parenthood. New York: New York University Press.

Berger, P.L. and T. Luckmann (1966) The Social Construction of Reality. New York: Penguin.

Bergstrom-Lynch, C. (2015) Lesbians, Gays, and Bisexuals Becoming Parents or Remaining Childfree: Confronting Social Inequalities. Lanham, MD: Lexington Books.

Berkowitz, D. and W. Marsiglio (2007) 'Gay Men: Negotiating Procreative, Father, and Family Identities', Journal of Marriage and Family 69: 366-81.

Bernstein, M. (2015) 'Same-sex Marriage and the Future of LGBT Movements', Gender \& Society 29: 321-37.

Canaday, M. (2009) The Straight State: Sexuality and Citizenship in 2oth-century America. Princeton, NJ: Princeton University Press.

Carroll, M. (2018) 'Managing without Moms: Gay Fathers, Incidental Activism, and the Politics of Parental Gender', Journal of Family Issues 39: 3410-35.

Choo, H.Y. and M.M. Ferree (2010) 'Practicing Intersectionality in Sociological Research: A Critical Analysis of Inclusions, Interactions, and Institutions in the Study of Inequalities', Sociological Theory 28: 129-49.

Collins, P.H. (2015) 'Intersectionality's Definitional Dilemmas', Annual Review of Sociology 41: 1-20.

Emerson, R., R. Fretz and L. Shaw (1995) Writing Ethnographic Fieldnotes. Chicago: University of Chicago Press.

Fenstermaker, S. and C. West (eds) (2002) Doing Gender, Doing Difference: Inequality, Power, and Institutional Change. New York: Routledge.

Fetner, T. (2016) 'U.S. Attitudes toward Lesbian and Gay People Are Better than Ever', Contexts 15: 20-7.

Fisher, A. (2003) 'Still "Not Quite as Good as Having Your Own"? Toward a Sociology of Adoption', Annual Review of Sociology 29: 336-61.

Gash, A. and J. Raiskin (2016) 'Parenting without Protection: How Legal Status Ambiguity Affects Lesbian and Gay Parenthood', Law \& Social Inquiry 43(1): 82-118.

Goldberg, A., L. Kinkler and D. Hines (2011) 'Perception and Internalization of Adoption Stigma among Gay, Lesbian, and Heterosexual Adoptive Parents', Journal of GLBT Family Studies 7: 132-54.

Gubrium, J.F. and J.A. Holstein (1990) What Is Family? Mountain View, CA: Mayfield.

Hays, S. (1994) 'Structure and Agency and the Sticky Problem of Culture', Sociological Theory 12: 57-72.

Hollander, J.A. (2013) “I Demand More of People”: Accountability, Interaction, and Gender Change', Gender \& Society 27: 5-29. 
Ingraham, C. (1999) White Weddings: Romancing Heterosexuality in Popular Culture. New York: Routledge.

Jackson, S. (2006) 'Gender, Sexuality and Heterosexuality: The Complexity (and Limits) of Heteronormativity', Feminist Theory 7: 105-21.

Jones, T. (2017a) 'Trump, Trans Students, and Transnational Progress', Sex Education 18: 497-94.

Jones, T. (2017b) 'Intersex and Families: Supporting Family Members with Intersex Variations', Journal of Family Strengths 17: Article 8.

Kazyak, E. (2015) “"The Law Is the Law, Right?” Sexual Minority Mothers Navigating Legal Inequities and Inconsistencies', Sexuality Research and Social Policy 12: 188-201.

Kazyak, E. and B. Woodell (2016) 'Law and LGBQ-parent Families', Sexuality \& Culture 20: 749-68.

Kazyak, E., N.K. Park, J. McQuillan and A.L. Greil (2016) 'Attitudes toward Motherhood among U.S. Sexual Minority Women', Journal of Family Issues 37: 1771-96.

Kazyak, E., B. Woodell, K. Scherrer and E. Finken (2018) 'Law and Family Formation among LGBQ-parent Families', Family Court Review 56: 364-73.

Kitzinger, C. (2005) 'Heteronormativity in Action: Reproducing the Heterosexual Nuclear Family in After-hours Medical Calls', Social Problems 52: 477-98.

Lewin, E. (2009) Gay Fatherhood: Narratives of Family and Citizenship in America. Chicago, IL: University of Chicago Press.

Martin, K. and E. Kazyak (2009) 'Hetero-romantic Love and Heterosexiness in Children's G-rated Films', Gender \& Society 2: 315-36.

McCall, L. (2005) 'The Complexity of Intersectionality', Signs: Journal of Women in Culture and Society 30: 1771-800.

Moore, M. (2011) Invisible Families: Gay Identities, Relationships, and Motherhood among Black Women. Berkeley: University of California Press.

Nelson, M.K. (2006) 'Single Mothers "Do Family”', Journal of Marriage and Family 68: 781-95.

Ochs, R. and S. Rowley (eds) (2009) Getting Bi: Voices of Bisexuals Around the World. Boston, MA: Bisexual Resource Center.

Oswald, R.F. (2002) 'Resilience within the Family Networks of Lesbians and Gay Men: Intentionality and Redefinition', Journal of Marriage and Family 64: 374-83.

Park, N.K., E. Kazyak and K. Slauson-Blevins (2016) 'How Law Shapes Experiences of Parenthood for Gay and Lesbian Couples', Journal of GLBT Family Studies 12: 115-37.

Patterson, C. and R.G. Riskind (2010) 'To Be a Parent: Issues in Family Formation among Gay and Lesbian Adults', Journal of GLBT Family Studies 6: 326-40.

Pfeffer, C. (2016) Queering Families: The Postmodern Partnerships of Cisgender Women and Transgender Men. New York: Oxford University Press. 
Powell, B., C. Bolzendahl, C. Geist and L.C. Steelman (2010) Counted Out: Samesex Relations and Americans' Definitions of Family. New York: Russell Sage.

Richman, K.D. (2009) Courting Change: Queer Parents, Judges, and the Transformation of American Family Law. New York: New York University Press.

Risman, B. (2004) 'Gender as a Social Structure: Theory Wrestling with Activism', Gender \& Society 18: 429-50.

Rubin, G. (1984) 'Thinking Sex: Notes for a Radical Theory of the Politics of Sexuality', in C.S. Vance, (ed.) Pleasure and Danger: Exploring Female Sexuality. New York: Routledge, pp. 267-319.

Scherrer, K.S., E. Kazyak and R. Schmitz (2015) 'Getting "Bi” in the Family: Bisexual People's Disclosure Experiences', Journal of Marriage and Family 77: 680-96.

Schilt, K. (2008) 'The Unfinished Business of Sexuality: Comment on Andersen', Gender \& Society 22: 109-14.

Seidman, S. (2002) Beyond the Closet. New York: Routledge.

Sewell, W.H. (1992) 'A Theory of Structure: Duality, Agency, and Transformation', American Journal of Sociology 98: 1-29.

Shapiro, D.N., C. Peterson and A. Stewart (2009) 'Legal and Social Contexts and Mental Health among Lesbian and Heterosexual Mothers', Journal of Family Psychology 23: 255-62.

Shapiro, J. (2013) 'The Law Governing LGBT-parent Families', in A. Goldberg and K. Allen (eds) LGBT-parent Families: Innovations in Research and Implications for Practice. New York: Springer, pp. 291-306.

Slauson-Blevins, K. and N. Park (2016) 'Deciding Not to Adopt: The Role of Normative Family Ideologies in Adoption Consideration', Adoption Quarterly 19: $237-60$.

Smith, D. (1993) 'The Standard North American Family: SNAF as an Ideological Code', Journal of Family Issues 14: 50-65.

Suter, E.A., K.L. Reyes and R.L. Ballard (2011) 'Adoptive Parents' Framing Laypersons' Conceptions of Family', Qualitative Research Reports in Communication 12: 43-50.

West, C. and S. Fenstermaker (1995) 'Doing Difference', Gender \& Society 9: 8-37.

West, C. and D.H. Zimmerman (1987) 'Doing Gender', Gender \& Society 1: 125-51.

West, C. and D.H. Zimmerman (2009) 'Accounting for Doing Gender', Gender \& Society 23: 112-22.

Weston, K. (1991) Families We Choose. New York: Columbia University Press. 


\section{Author biographies}

Emily Kazyak is an Associate Professor of Sociology and Women's and Gender Studies at the University of Nebraska - Lincoln. Her research examines the changing cultural and legal landscape related to sexuality in the United States. Her most recent work includes a nation-wide study of religious exemption laws related to LGBTQ people, which is funded by the National Science Foundation. Her work appears in numerous journals including Gender \& Society, Sexuality Research and Social Policy and Journal of Marriage and Family.

Nicholas K. Park is a sociology instructor at Gavilan College. His research centers on the sociology of families broadly, with particular attention on adoption, infertility, motherhood and fatherhood, and LGBTQ parents. His research has appeared in journals such as Journal of Family Issues, Journal of GLBT Family Studies and Adoption Quarterly. 